\title{
THERMAL WORK LIMIT INDEX IN CATTLE FARM
}

\author{
Dimo Dimov¹, Ivaylo Marinov², Toncho Penev ${ }^{1}$ \\ ${ }^{1}$ Department of Applied Ecology and Animal Hygiene, Faculty of Agriculture, Trakia University, 6000 Stara \\ Zagora, Bulgaria \\ ${ }^{2}$ Department of Animal Husbandry - Ruminants and Dairy Farming, Faculty of Agriculture, Trakia University, \\ 6000 Stara Zagora, Bulgaria
}

Link to this article: https://doi.org/10.11118/actaun.2021.016

Received: 25. 1. 2021, Accepted: 16. 2. 2021

To cite this article: DIMOV DIMO, MARINOV IVAYLO, PENEV TONCHO. 2021. Thermal Work Limit Index in Cattle Farm. Acta Universitatis Agriculturae et Silviculturae Mendelianae Brunensis, 69(2): 199-202.

\begin{abstract}
The survey was conducted in workers in dairy farming in Bulgaria. In the survey were not reported Thermal Work Limit (TWL) index values, which require cessation of employment and constitute a danger to human health. The lowest values of TWL were registered during the summer and spring months, respectively 229.3 and $258.4 \mathrm{~W} / \mathrm{m}^{2}$. The highest are normally registered in the autumn and winter months -318.3 and $312.2 \mathrm{~W} / \mathrm{m}^{2}$. Outdoor the lowest average TWL values were reported in the summer and spring months 236 and $287.9 \mathrm{~W} / \mathrm{m}^{2}$, respectively, and the highest in the autumn and winter months - 316.4 and $317.2 \mathrm{~W} / \mathrm{m}^{2}$. An inverse dependency was found between the calculated values of Temperature-humidity index (THI) and the TWL.
\end{abstract}

Keywords: TWL, THI

\section{INTRODUCTION}

The large number of workers employed in construction, agriculture and other work activities are directly exposed to the effects of outside temperatures, which leads to heat stress, which is a problem that will exacerbating by the global rise in planet temperature (Miller and Bates, 2007). When working in such conditions, an easy and reliable tool is needed to monitor the heat stress among workers in order to avoid any harm to their health. The ideal heat stress index is one that is easy to determine, reliable, unambiguous and does not require specific knowledge for its interpretation. Exactly such an improvement is the TWL (Bates and Miller, 2002). This index is included by the Australian Institute of Occupational Health (AIOH) as a standard for heat stress (Brake, 2004). The TWL became the standard for working in underground mines in 2008 in Australia, probably one of the most unfavorable working environments. This index has been shown to be more realistic and reliable for determining heat stress in workers than other existing indices (Brake, 2004; Miller and Bates, 2007), and it is easier to use and less prone to error in its interpretation (Bates and Schneider, 2008). TWL is particularly suitable in situations where there is significant cooling associated with air movement. Brake and Bates (2002a) report that it has been introduced into a number of industrial operations carried out in the tropical climate zone, which the authors believe has led to a significant and lasting reduction in the incidence of heat illness in workers. According to them, this index is suitable for use by the construction industry. The human body can be quite resistant to heat stress after physiological adaptation that occurs among those living or working in a hot environment. The process of acclimatization allows people to withstand heat stress without suffering from heat diseases. This includes a number of physiological and biochemical changes, the first being physical ability to improve heart function. This allows a significant increase in blood flow to the skin without excessively restricting the supply of oxygen to other important tissues. Second, the plasma volume of the circulatory system increases, as well as the renal blood flow. This leads to a reduction in kidney damage (Charkoudian, 2003). 
Workers in different industries may have different degrees of sensitivity to heat stress. More in-depth research is needed in various work fields, which will give a more accurate picture of the state of workers under conditions of heat stress. With the help of TWL, a set of good practices can be developed to ensure the health and safety of workers in hot weather. This would be of great benefit to protect the health and safety of workers by reducing the incidence of heat stroke in workers (Chan et al., 2012).

In the world and our scientific literature there is no data on the use of this index in agricultural workers and in particular in workers employed in dairy cattle farming, which give us reason to conduct such a study. The purpose of this study was to determine the TWL for workers employed in dairy cattle farming in Bulgaria.

\section{MATERIALS AND METHODS}

The research was conducted in a cattle farm located in Southern Bulgaria. In the farm cows of the breed Holstein-Friesian were reared. The capacity of the farm was 500 dairy cows. At the time of the study, there were 150 available cows that were milked. The cows were housed in free-stall semiopen dairy barn. The cows were milked three times a day in a double-8 "herringbone" milking parlor. The workers employed with a contract on the farm were five. The work shift was within eight hour. All the workers were male, aged 40 to 55 years.

The reporting of the TWL was carried out in a period of one year, as in the summer months, when it was expected an occurrence of problem with heat, the measurements were made several

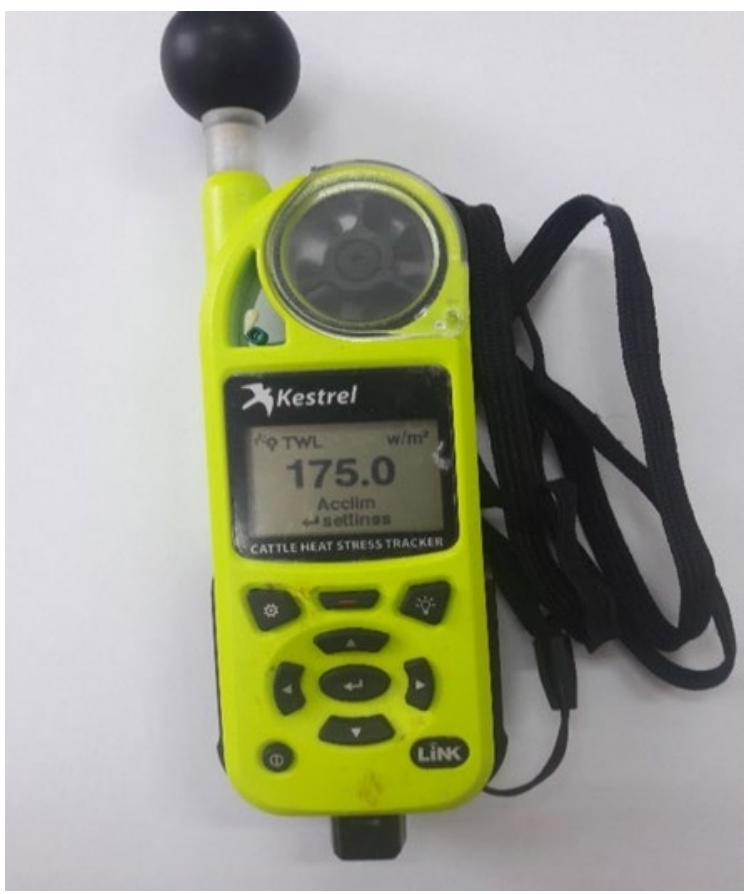

1: Meteorological station Kestrel times a month. The index was reported always at the same hours: 10:00 h; 12:00 h; 14:00 h; 16:00 h and 18:00 h, inside the livestock premises in precisely defined and evenly spaced from each other points, the measuring was done at a distance of $1 \mathrm{~m}$ from the floor of the premises.

The measurement of the index values was done with the help of Kestrel meteorological station (Fig. 1). This weather station automatically determines the values of the index.

Five environmental indicators were used to determine this index (dry and wet bulb temperature, so-called global temperature, air velocity and atmospheric pressure level), the unit of measurement was W/m² (Miller and Bates, 2007).

Basic statistical data processing was performed using MS Excel, and mean values and errors using STATISTICA by StatSoft (Copyright 1990-1995 Microsoft Corp.). Basic statistical data processing was performed using MS Excel, and mean values and errors using STATISTICA by StatSoft (Copyright 1990-1995 Microsoft Corp.).

To assess the influence of factors, general models were used:

$$
Y_{i j k l}=\mu+A_{i}+B_{j}+e_{i j k},
$$

where:

$Y_{i j k l}$. was the dependent variable (work environment); $\mu \ldots . .$. was the average for the model;

$A_{i} \ldots . .$. was the effect of fixed factors (represented in classes),

$B_{j} \ldots . .$. was the effect of non-class, independent variables in real values and

$e_{i j k} \ldots$. was the effect of non-included, random factors.

The data were analyzed using Harvey's (1987) computer program LSMLMW. By analysis of variance (ANOVA) for each model was obtained the least squares of mean (LSM) by classes of the fixed factors.

\section{RESULTS}

Tab. I shows the average values and standard deviation of the index of TWL inside the livestock premise. The lowest values were registered during the summer and spring months, respectively 229.3 and $258.4 \mathrm{~W} / \mathrm{m}^{2}$. The highest were registered naturally in the autumn and winter months - 318.3 and $312.2 \mathrm{~W} / \mathrm{m}^{2}$

I: Average values and standard deviation of the index of TWL by seasons inside the livestock premise

\begin{tabular}{lccccc}
\hline \multirow{2}{*}{ Season } & \multirow{2}{*}{ Number N } & \multicolumn{5}{c}{ TWL, W/m } \\
\cline { 4 - 7 } & & $\mathrm{X} \pm \mathrm{Se}$ & $\mathrm{SD}$ & $\mathrm{Min}$ & $\mathrm{Max}$ \\
\hline Summer & 15 & $229.3 \pm 5.84$ & 22.62 & 191 & 273.3 \\
Autumn & 10 & $318.3 \pm 1.32$ & 4.17 & 307 & 320 \\
Winter & 5 & $312.2 \pm 2.59$ & 5.79 & 306 & 320 \\
Spring & 19 & $258.4 \pm 9.87$ & 43.04 & 192.8 & 320 \\
\hline
\end{tabular}


Tab. II presents the average values and standard deviation of the TWL index outside the premise. Again, the lowest average values of the index were reported in the summer and spring months, respectively 236 and $287.9 \mathrm{~W} / \mathrm{m}^{2}$, and the highest average values were reported in the autumn and winter months - 316.4 and $317.2 \mathrm{~W} / \mathrm{m}^{2}$. Here, however, the minimum reached value of the index was $177 \mathrm{~W} / \mathrm{m}^{2}$ in summer and inside the premise the lowest reported value is $190 \mathrm{~W} / \mathrm{m}^{2}$. This was most likely due to the fact that in summer the sun emits much stronger heat radiation and the reporting of the index from the outside leads to the registration of lower values.

The average outside values, except for the autumn season, was higher than those obtained for the index indoors. This was because a higher air velocity was registered outside as opposed to that indoors, which contributed to the cooling.

The highest average values of THI were registered in the summer season 73.82, and the lowest in the autumn season - 52.01 (Tab. III). During the summer season, however, a maximum value of 78.6 was reached.

II: Average values and standard deviation of the index of TWL by seasons outside the livestock premise

\begin{tabular}{|c|c|c|c|c|c|}
\hline \multirow{2}{*}{ Season } & \multirow{2}{*}{ Number $\mathrm{N}$} & \multicolumn{4}{|c|}{ TWL, W/m² } \\
\hline & & $\mathrm{X} \pm \mathrm{Se}$ & SD & Min & Max \\
\hline Summer & 15 & $236 \pm 10.54$ & 40.81 & 177.8 & 303.1 \\
\hline Autumn & 10 & $316.4 \pm 1.93$ & 6.09 & 304.1 & 320 \\
\hline Winter & 5 & $317.2 \pm 2.76$ & 6.17 & 306.2 & 320 \\
\hline Spring & 19 & $287.9 \pm 7.47$ & 32.5 & 211 & 320 \\
\hline
\end{tabular}

III: Average values and standard deviation of the THI by seasons inside the livestock premise

\begin{tabular}{lccccc}
\hline \multirow{2}{*}{ Season } & \multirow{2}{*}{ Number $\mathrm{N}$} & \multicolumn{4}{c}{ TWL, W/m } \\
\cline { 4 - 7 } & & $\mathrm{X} \pm \mathrm{Se}$ & $\mathrm{SD}$ & $\mathrm{Min}$ & $\mathrm{Max}$ \\
\hline Summer & 15 & $73.82 \pm 0.55$ & 2.14 & 70.1 & 78.6 \\
Autumn & 10 & $52.01 \pm 0.95$ & 3.02 & 48.5 & 56.6 \\
Winter & 5 & $55.64 \pm 0.44$ & 0.19 & 55.2 & 56.2 \\
Spring & 19 & $67.99 \pm 2.25$ & 9.82 & 50.7 & 77.3 \\
\hline
\end{tabular}

IV: Average values and standard deviation of the THI by seasons outside the livestock premise

\begin{tabular}{lccccc}
\hline \multirow{2}{*}{ Season } & \multirow{2}{*}{ Number N N } & \multicolumn{5}{c}{ TWL, W/m } \\
\cline { 4 - 6 } & & $\mathrm{X} \pm \mathrm{Se}$ & $\mathrm{SD}$ & $\mathrm{Min}$ & $\mathrm{Max}$ \\
\hline Summer & 15 & $74.52 \pm 0.38$ & 1.45 & 72.5 & 77.6 \\
Autumn & 10 & $51.1 \pm 0.95$ & 1.2 & 46.3 & 56.2 \\
Winter & 5 & $56.4 \pm 0.25$ & 0.57 & 55.5 & 57 \\
Spring & 19 & $66.78 \pm 2.33$ & 10.14 & 48.6 & 77.8 \\
\hline
\end{tabular}

V: Average values of the TWL index inside the livestock premises depending on the THI values

\begin{tabular}{lccccc}
\hline & \multirow{2}{*}{ THI } & Number N & \multicolumn{5}{c}{ TWL, W/m } \\
\cline { 3 - 6 } & & $\mathrm{X} \pm \mathrm{Se}$ & $\mathrm{SD}$ & $\mathrm{Min}$ & $\mathrm{Max}$ \\
\hline 1 & 20 & $317.1 \pm 1.09$ & 4.88 & 306.6 & 320 \\
2 & 29 & $232.8 \pm 4.36$ & 23.5 & 191 & 280 \\
\hline
\end{tabular}

Tab. IV shows the average values and standard deviation of the THI outside the premise. The highest values were logically reported in the summer season 74.52. The lowest average values were registered again in the autumn season 51.1. Here, as in the case of the values obtained inside the livestock premises, only for the summer season we have reaching of values close the danger zone. The difference between the obtained values of THI inside and outside was insignificant within 1.5 units.

Tab. V presents a descriptive analysis between the THI and the TWL index.

To achieve a better approximation in data processing, the values of THI were divided into classes according to the recommendation of Dragotă (2003) as follows: values below 65 in class 1; values from 66 to 79 in class 2; values greater than 80 in class 3 . The highest TWL values corresponded to the class with the lowest THI values, and the lowest TWL values corresponded to the class with the highest THI values. No third class THI values were reached.

\section{DISCUSSION}

The selected farm was located in Southern Bulgaria, where summer temperatures reach values that are a prerequisite for heat stress in people not performing any work, and even more so for active workers. The farm was in a climatic zone characterized by a transitional continental climate. This climatic zone covers the entire Upper Thracian lowland, the low Trans-Balkan valleys, the northern part of the Tundzha river hilly and lowland region and the Eastern Stara Planina. The average January temperature is from -1.5 to $+1^{\circ} \mathrm{C}$, the average July temperature is $22-24^{\circ} \mathrm{C}$, and the maximum summer temperatures reach $40^{\circ} \mathrm{C}$ (Alexandrov, 2006).

According to Brake and Bates, (2002b) at values of the index $<115 \mathrm{~W} / \mathrm{m}^{2}$ it is necessary to stop work; values from 115 to $140 \mathrm{~W} / \mathrm{m}^{2}$ are considered as a buffer zone; values from 141 to $220 \mathrm{~W} / \mathrm{m}^{2}$ acclimatization zone and values $>220 \mathrm{~W} / \mathrm{m}^{2}$ are designated as safe values. Referring the values obtained by us to the given recommendation, they fall into the safe zone without danger to human health (Tab. I). During the summer months, a minimum value of this index of $190 \mathrm{~W} / \mathrm{m}^{2}$ was reached, which value falls into the acclimatization zone, which is also not dangerous for human health and work can continue normally. 
Most people feel comfortable at THI values below 70. Dangerous THI values for human health are from 80-85 (Encyclopedia Britannica, 2010). According to Dragotă (2003), values of THI below 65 are comfortable for humans, between 66-79 are "alarming" values at which it is necessary to take action and values above 80 - dangerous to human health. The results obtained by us did not reach THI values dangerous for human health (Tab. IV), only for the summer season we had values that were potentially dangerous and it was necessary to take action to reduce them in order not to reach threateningly high levels.

The separation of THI into classes was made since it is a commonly used index to determine heat stress in humans and animals. Initially, this index was used only for humans (Thom, 1959), but it was quickly adopted and began to be used in various species of animals (Lendelova and Botto, 2011). Therefore we looked for a relationship at which THI values which TWL index values correspond.

\section{CONCLUSION}

In the survey were not reported TWL index values, which require cessation of employment and constitute a danger to human health. An inverse dependency between the obtained values of THI and the index of TWL was found. Therefore, very low TWL values can be expected at very high THI values, which are a prerequisite for heat stress not only in dairy cows, but also in people working in such conditions.

The Kestrel device is successfully used to determine heat stress in cows, it is also set to automatically determine the index of TWL. Farmers can easily use it to determine not only the heat stress in their animals, but also in the workers they employ, and thus, in the event of a problem, to take timely measures for the safety of both the animals and the people who work with them.

\section{REFERENCES}

ALEXANDROV, V. 2006. Report on the spatial distribution of soil drought in Bulgaria [in Bulgarian: Отчет върху пространственото разпределение на почвеното засушаване в България]. Sofia: Agronet.

BATES, G. and MILLER, V. 2002. Empirical validation of a new heat stress index. International Journal of Occupational Health and Safety, 18(2): 145-153.

BATES, G. P. and SCHNEIDER, J. 2008. Hydration status and physiological workload of UAE construction workers: A prospective longitudinal observational study. J Occup. Med. Toxicol., 3: 21.

BRAKE, D. J. 2004. The application of a rational heat stress index (Thermal Work Limit) to sports medicine. Journal of Science and Medicine in Sport, 7(4): 102.

BRAKE, D. J. and BATES, G. P. 2002a. Limiting metabolic rate (thermal work limit) as an index of thermal stress. Applied Occupational and Environmental Hygiene, 17(3): 176-186.

BRAKE, R. and BATES, G. 2002b. A valid method for comparing rational and empirical heat stress indices. Annals of Occupational Hygiene, 46(2): 165-174.

CHAN, A. P. C., YI, W., CHAN, D. W. M. et al. 2013. Using the Thermal Work Limit (TWL) as an Environmental Determinant of Heat Stress for Construction Workers. Journal of Management in Engineering, 29(4): 414-423.

CHARKOUDIAN, N. 2003. Skin blood flow in adult human thermoregulation: how it works, when it does not, and why. Mayo Clin. Proc., 78(5): 603-612.

DRAGOTĂ, C. 2003. Comfort Indices - Temperature-humidity index (THI), Indices and methods used in climatology [in Romanian: Indicele de confort temperatură-umezeală (ITU), Indici si metode cantitative utilizate in climatologie]. Oradea: Edit. Univ. din Oradea.

ENCYCLOPAEDIA BRITANICA. 2010. Temperature-humidity index. Britannica. [Online]. Available at: www. britannica.com/EBchecked/topic/586706/temperature-humidity-index [Accessed: 2021, March 15].

LENDELOVA, J. and BOTTO, L. 2011. Evaluation of thermal-humidity index in animal housing. Bioclimate: In: Source and Limit of Social Development International Scientific Conference. $6^{\text {th }}-9^{\text {th }}$ September 2011, Topol'čianky, Slovakia.

MILLER, V. S. and BATES, G. P. 2007. The Thermal Work Limit is a simple reliable heat index for the protection of workers in thermally stressful environments. Annals of Occupational Hygiene, 51(6): 553-561.

THOM, E. C. 1959. The discomfort index. Weatherwise, 12(2): 57-59.

Contact information

Ivaylo Marinov: marinov.ib@abv.bg 